\title{
PEMBUATAN CUKA ALAMI BUAH SALAK DAN PISANG KEPOK BESERTA KULITNYA TEKNIK FERMENTASI
}

\author{
Dwi Ratna Febriani' ${ }^{*}$, Zidni Azizati \\ ${ }_{1}^{1}$ Program Sarjana Jurusan Kimia Fakultas Sains dan Teknologi UIN Walisongo Semarang, Indonesia \\ 2Jurusan Kimia Fakultas Sains dan Teknologi UIN Walisongo Semarang, Indonesia \\ *Email: dwiratnafebriani@gmail.com
}

\begin{abstract}
s
Cuka adalah suatu zat yang dibuat dari berbagai bahan yang bergula atau berpati melalui fermentasi alkohol yang diikuti oleh fermentasi asetat. Cuka yang beredar di masyarakat biasanya terbuat dari bahan-bahan kimia yang berbahaya bagi tubuh, secara industri dengan menggunakan metode sintesis kimia murni. Untuk itu perlu dibuat inovasi alami dalam pembuatan cuka buah yaitu salak dan pisang kepok beserta kulitnya. Buah salak dan pisang kepok merupakan buah yang banyak terdapat di berbagai wilayah Indonesia yang mengandung kadar karbohidrat yang tinggi sehinggga dapat dimanfaatkan sebagai bahan baku pembuatan cuka. Tujuan dari penelitian ini adalah untuk mengetahui efektifitas pembuatan cuka alami buah salak dan pisang kepok beserta kulitnya dengan teknik fermentasi. Hasil penelitian menunjukan bahwa kadar asam cuka sebesar 0,042 \%, memiliki aroma yang kurang sedap,larutan berwarna putih dan nilai pH 4,5 sehingga belum memenuhi kadar cuka yang dipasarkan dan dikonsumsi masyarakat yaitu minimal $4 \%(4 \mathrm{~g}$ asam asetat per $100 \mathrm{ml})$.
\end{abstract}

Kata kunci : Cuka; salak; pisang kepok; kulit pisang kepok; fermentasi

\section{Pendahuluan}

Cuka adalah suatu zat yang dibuat dari berbagai bahan yang bergula atau berpati melalui fermentasi alkohol yan diikuti oleh fermentasi asetat. Produk ini merupakan suatu larutan asam asetat dalam air yang megandung cita rasa, zat warna dan substansi yang terekstrak, asam buah, ester-ester, garam-garam organik dari buah, yang berbeda-beda sesuai dengan asalnya (Desrosier, 1988).

72
Pembuatan cuka didasarkan pada dua prinsip yaitu fermentasi alkohol dan asetat. Prinsip pertama dilakukan dengan menggunakan bantuan Saccharomyces cereviciae yang mengubah kandungan gula sederhana atau pati menjadi alkohol dalam kondisi anaerob (tanpa udara). Tahap ini dapat bekerja secara optiimal jika pada $\mathrm{pH}$ 3,5-6,0, dan pada suhu yang efisien 28-35 ${ }^{\circ} \mathrm{C}$. (Zubaidah, 2010).

Sedangkan pada tahap kedua dilakukan fermentasi asetat dengan menggunakan bakteri

Copyright (C) 2018 WJC | ISSN 2621-5985 (online) | ISSN 2549-385X (print)

Volume 1, Nomor 2, 2018 
Acccetobacter, misalnya Acccetobacter Acety, xylinum, acetyginum,dan pasteurinus. (Weisher, at all, 1971). Acetobacter aceti yang mengubah alkohol dengan kadar tertentu menjadi sejumlah asam asetat dalam kondisi aerob, pada suhu optimum $15-34{ }^{\circ} \mathrm{C}, \mathrm{pH} 3,0-4,0$. Kriteria mutu cuka yang utama adalah kandungan asam asetatnya. (Zubaidah, 2010).

Cuka yang dijual harus mengandung paling sedikit 4\% (4 g asam asetat per $100 \mathrm{ml}$ ), harus segar dan dibuat dari buah-buahan yang layak dikonsumsi serta harus diberi label yang semestinya (Desrosier, 1988).

Cuka yang sudah banyak beredar di pasar dan dikonsumsi oleh mayarakat terbuat dari bahan-bahan kimia yang berbahaya bagi tubuh. Biasanya cuka dibuat secara industri dengan menggunakan metode sintesis kimia murni. Untuk itu perlu dibuat inovasi alami dalam pembuatan cuka misalnya dengan ,menggunakan buah.

Pisang dan salak merupakan tanaman yang banyak terdapat di Indonesia dan dapat tumbuh setiap musimnya sehinga jumlahnya selalu melimpah. Pisang mempunyai kandungan gizi sangat baik, kaya mineral seperti kalium, magnesium, fosfor, besi, dan kalsium, mengandung beberapa jenis senyawa antioksidan yang dapat diisolasi dari kulit pisang yaitu asam amino, peptida, flavonoid, katekolamin, dopamin dan polimer dopamin,s serta mengandung 18-25\% karbohidrat. (Humairani, 2007).

Kabupaten Banjarnegara merupakan salah satu daerah penghasil salak berkualitas di Jawa Tengah, Indonesia. Memiliki cita rasa yang khas yaitu rasa manis. Salak Pondoh Banjarnegara dapat dijumpai di wilayah pegunungan kecamatan Madukoro, Pagentan, dan Pagedongan. Dalam setiap panen, harga satu kg salak hanya sebesar Rp.1500/kg jika dalam musimnya. Itu pun salak yang memiliki kualitas yang baik dan super.

Masyarakat Banjarnegara, biasanya mengkonsumsi salak secara langsung, dibuat berbagai makanan dan minuman misalnya selai, sirup, manisan, keripik dan puding. Pemanfaatan buah salak sebagai pembuatan cuka buah alami belum dilakukan sehingga hal ini dapat menjadi nilai jual bagi mayarakat dan dapat meningkatkan penghasilan masyarakat dengan membuatnya sendiri dan kemudian dapat diperjual belikan. Selain itu buah salak berkhasiat sebagai antioksidan, menjaga kesehatan mata, antidiabetes, menurunkan kolesterol, dan antidiare. Berfungsi sebagai antioksidan karena didalamnya mengandung senyawa senyawa fenolik golongan flavonoid. (Apak et al, 2007).

Dalam penelitian sebelumnya telah dimanfaatkan pisang kepok sebagai bahan pmebuatan cuka buah alami dengan Acetobacter acety. (Rudi, 2004). Begitu juga dengan buah salak yaitu dengan bakteri Acetobacter acety (Rahayu, 2015). Bakteri Acctobacter xylinum dapat juga digunakan dalam pembuatan cuka misalnya cuka buah seri (Muntingja Calabura L). (Fikri)

Berdasar penelitian tersebut, salak dan pisang terbukti dapat digunakan sebagai bahan baku cuka alami. Namun, belum dilakukan penelitian dengan mengkombinasikan buah salak dan pisang kepok sebagai pembuatan cuka buah alami.

Tujuan dari penelitian ini adalah untuk mengetahui efektifitas pembuatan cuka alami buah salak dan pisang kepok serta kulitnya dengan teknik fermentasi. 


\section{Metode Penelitian}

Penelitian dilakukan di Laboratorium Kimia Fakultas Sains dan Teknologi UIN Walisongo Semarang dalam 3 tahapan.

\begin{tabular}{|l|l|l|}
\hline No & Tahap & Waktu \\
\hline 1 & Fermentasi I & Rabu, 25 April 2018 \\
\hline 2 & Ferementasi II & Rabu, 2 Mei 2018 \\
\hline 3 & $\begin{array}{l}\text { Analisis Kadar } \\
\text { Cuka }\end{array}$ & $\begin{array}{l}\text { Jum'at, 11 Mei } \\
2018\end{array}$ \\
\hline
\end{tabular}

Alat dan Bahan

Alat yang digunakan dalam penelitian ini antara lain pisau, baskom, neraca analitik, erlenmeyer $250 \mathrm{ml}$, gelas ukur $100 \mathrm{ml}$, beaker glass $500 \mathrm{ml}$, hot plate, magnetic stirrer, blender, buret $50 \mathrm{ml}$, pipet tetes, corong, toples dan kain saring. Bahan yang digunakan adalah buah salak, buah pisang kepok, kulit pisang kepok, Sacharomiches cereviceae, , aquades, $\mathrm{NaOH} 0,1 \mathrm{M}$, urea, indikator phenolphtalin, aluminum foil, Acetobacter xylinum, dan kertas saring.

Prosedur Kerja

Pelaksanaan penelitian ini diawali dengan pengupasan buah salak, pencucian, penimbangan, penghalusan, penyaringan, perebusan, fermentasi I dengan Saccharomyces cereviciae dan fermentasi II Acetobacter xylinum serta analisis kadar cuka. Cuka buah yang diperoleh kemudian diamati parameter fisiknya yaitu aroma, warna, dan $\mathrm{pH}$.

Fermentasi I

Setelah didapatkan filtrat dari proses pengupasan buah, pencucuian, penimbangan sebanyak 216, 67 gram, pengahalusan, penyaringan dan perebusan, maka langakh selanjutnya adalah feremntasi I menggunakan
Saccharomyces cereviciae dan 2,5 g urea di masukkan dalam toples, diaduk dan ditutup rapat. Proses dilakukan dalam keadaan anaerob sehingga harus ditutup rapat selama 7 hari sehingga akan dihasilkan alkohol.

Fermentasi II

Hasil dari fermentasi I kemudian di fermentasi kembali menggunakann Accetobacter xylinum $100 \mathrm{ml}$ selama 9 hari untuk menghasilkan cuka.

Analisa Kadar Cuka

Menggunakan metode asidi alkalimetri dengan larutan standar $\mathrm{NaOH}$ 0,1 M. $10 \mathrm{ml}$ asam cuka diambil dan diencerkan menjadi $100 \mathrm{ml}$. Sebanyak 3 sampel diisi dengan larutan cuka $10 \mathrm{ml}$ yang sudah diencerkan kemudian dititrasi dengan $\mathrm{NaOH}$ 0,1M. Konsentrasi asam cuka dicari dengan menggunakan rumus :

\section{$\mathrm{Va} . \mathrm{Ma}=\mathrm{Vb} . \mathrm{Mb}$}

Mencari kadar asam cuka adalah menggunakan rumus :

$$
\text { Kadar }=\frac{\mathrm{V} \mathrm{NaOH} . \mathrm{M} \mathrm{NaOH} . \mathrm{Mr} \mathrm{CH}_{3} \mathrm{COOH} . \mathrm{F} \mathrm{p} .}{\mathrm{W} .1000}
$$

\section{Hasil dan Pembahasan}

Pelaksanaan penelitian dilakukan selama 3 minggu dan 3 tahap yaitu fermentasi I, fermentasi II, dan analisis kadar cuka buah.

Fermentasi I

Buah salak dan pisang kepok besera kulitnya di fermentasi dengan Saccharomyces cereviciae selama 7 hari dengan tujuan untuk mengubah kandungan gula sederhana atau pati menjadi alkohol dalam kondisi anaerob (tanpa udara). 


\begin{tabular}{|c|c|c|c|c|c|}
\hline Fementasi & \begin{tabular}{|l} 
Volume \\
Lanutan
\end{tabular} & $\begin{array}{l}\text { Wama(sebehm } \\
\text { penyaringan) }\end{array}$ & $\begin{array}{l}\text { Wama(setelah } \\
\text { penyaringan) }\end{array}$ & Aroma & $\mathrm{pH}$ \\
\hline Awal & $650 \mathrm{ml}$ & - & - & $\begin{array}{l}\text { Aroma } \\
\text { buah } \\
\text { Salak } \\
\text { dan } \\
\text { Pisang }\end{array}$ & - \\
\hline 7 hari & $650 \mathrm{ml}$ & $\begin{array}{l}\text { Kuning } \\
\text { (keruh)+jamur } \\
\text { banyak } \\
\text { berwama putih } \\
\text { di atas } \\
\text { permukaan }\end{array}$ & $\begin{array}{l}\text { Kuning keruh } \\
\text { dantidak ada } \\
\text { jamur }\end{array}$ & $\begin{array}{l}\text { Aroma } \\
\text { tidak } \\
\text { sedap }\end{array}$ & 4,5 \\
\hline
\end{tabular}

Tabel 1. Hasil Fermentasi I

Dari tabel tersebut dapat dijelaskan bahwa cuka buah beraroma tidak sedap, larutan berwarna kuning (keruh) dan jamur berwarna putih sehingga harus di saring terlebih dahulu. Cuka dilihat nilai $\mathrm{pH}$ dengan menggunakan indikator universal yaitu sebesar 4,5 (bersifat asam).

$\mathrm{C}_{6} \mathrm{H}_{12} \mathrm{O}_{6} \rightarrow 2 \mathrm{C}_{2} \mathrm{H}_{5} \mathrm{OH}+2 \mathrm{CO}_{2}+2$ ATP (Sacharomyces cerevisiae)

Fermentasi II

Hasil Fermentasi I kemudian di fermentasi kembali dengan mengunakan bakteri Accetobacter xylinum. Tujuan dari fermentasi ini adalah untuk mengubah alkohol menjadi asetat dengan waktu fermentasi 9 hari.

\begin{tabular}{|c|c|c|c|c|c|}
\hline Fementasi & $\begin{array}{l}\text { Volume } \\
\text { Lanutan }\end{array}$ & Wama & $\begin{array}{c}\text {-Xylinum } 100 \\
\mathrm{ml}\end{array}$ & Aroma & $\mathrm{pH}$ \\
\hline Awal & $500 \mathrm{ml}$ & $\begin{array}{c}\text { Kuning kenuh } \\
\text { dan tidak ada } \\
\text { jamur }\end{array}$ & Beningkenuh & $\begin{array}{l}\text { Aroma } \\
\text { tidak } \\
\text { sedap }\end{array}$ & 4,5 \\
\hline 9 hani & $500 \mathrm{ml}$ & $\begin{array}{l}\text { Bening sedikit } \\
\text { kenuh \&sedikit } \\
\text { terdapatjamur }\end{array}$ & & $\begin{array}{l}\text { Aroma } \\
\text { buah } \\
\text { sedikit } \\
\text { tidak } \\
\text { sedap }\end{array}$ & 4,5 \\
\hline
\end{tabular}

Tabel 2. Hasil Fermentasi II

Dari tabel tersebut dapat dijelaskan bahwa cuka buah beraroma sediki sedap, larutan berwarna kuning ( sedikit keruh) dan jamur berwarna putih sehingga harus di saring terlebih dahulu. Cuka dilihat nilai $\mathrm{pH}$ dengan menggunakan indikator universal yaitu sebesar 4,5 (bersifat asam).

$\mathrm{C}_{2} \mathrm{H}_{5} \mathrm{OH}+\mathrm{O}_{2} \rightarrow \mathrm{CH}_{3} \mathrm{COOH}+\mathrm{H}_{2} \mathrm{O}$ (Acetobacter xylinum)

\section{Analisis Kadar Cuka}

Cuka yang telah melalui tahap fermentasi I dan II kemudian dianalisa berapa banyak kadarnya dengan menggunakan metode asidi alkalimetri yaitu dengan $\mathrm{NaOH} \mathrm{0,1} \mathrm{M} \mathrm{dan} \mathrm{indikator}$ phenolphtalin. Penggunaan indikator bertujuan untuk mengetahui titik akhir titrasi. Reaksi yang terjadi:

$\mathrm{CH}_{3} \mathrm{COOH}_{(\mathrm{aq})}+\mathrm{NaOH}_{(\mathrm{aq})} \longrightarrow \mathrm{CH}_{3} \mathrm{COONa}_{(\mathrm{aq})}+\mathrm{H}_{2} \mathrm{O}_{(\mathrm{aq})}$ 


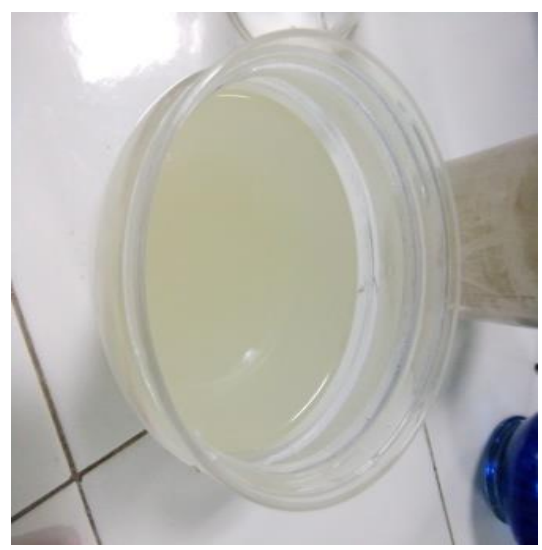

Gambar 1. Hasil cuka salak+pisang kepok

Asam cuka buah yang terbentuk memiliki aroma yang kurang sedap, larutan berwarna putih dan $\mathrm{pH} 4,5$.

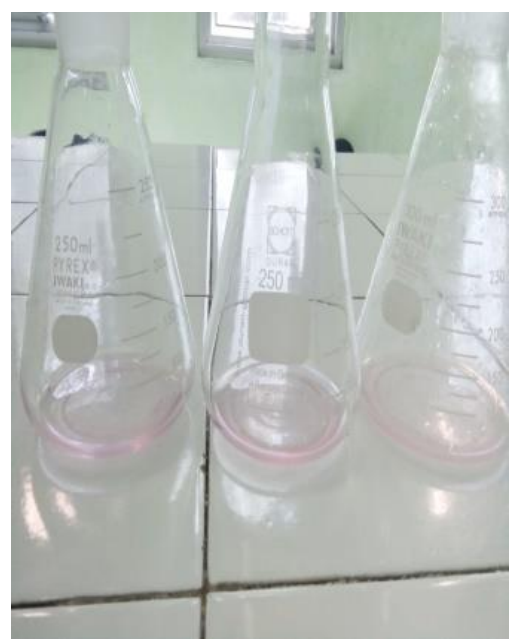

Gambar 2. Hasil Analisis Kadar Cuka

Titrasi dilkukan 3 kali percobaan sampai terjadi perubahan warna dari bening menjadi merah muda.

\begin{tabular}{|c|c|c|c|c|}
\hline $\begin{array}{c}\text { Percobaan } \\
\text { ke- }\end{array}$ & $\begin{array}{c}\text { Volume } \\
\mathrm{CH} \\
{ }_{3} \mathrm{COOH}\end{array}$ & \begin{tabular}{|c} 
Volume \\
$\mathrm{NaOH}$ \\
$0,1 \mathrm{~N}$
\end{tabular} & $\begin{array}{c}\text { Konsentrasi } \\
\mathrm{CH}_{3} \mathrm{COOH}\end{array}$ & $\begin{array}{c}\text { Perubahan } \\
\text { Warna }\end{array}$ \\
\hline 1 & $10 \mathrm{ml}$ & $0,7 \mathrm{ml}$ & & \\
\hline 2 & $10 \mathrm{ml}$ & $0,8 \mathrm{ml}$ & & \\
\hline 3 & $10 \mathrm{ml}$ & $0,6 \mathrm{ml}$ & & Bening - \\
\hline Rata-rata & $10 \mathrm{ml}$ & $0,7 \mathrm{ml}$ & $0,007 \mathrm{M}$ & $\begin{array}{l}\text { merah } \\
\text { muda }\end{array}$ \\
\hline
\end{tabular}

Titrasi bertujuan untuk mencari konsentrasi suatu larutan yang belum diketahui secara pasti, kemudian dapat digunakan unuk mencari kadar asam asetat yang didapat dari cuka buah tersebut

Berdasar langkah-langkah tersebut diperoleh kadar asam cuka buah salak yang dikombinasikan dengan pisang dan kulitnya sebesar 0,042\%.

Kadar ini tidak memenuhi syarat cuka yang diperdagangkan dan dikonsumsi oleh masyarakat sebesar $4 \%$ ( $4 \mathrm{~g}$ asam asetat per $100 \mathrm{ml}$ ), harus segar dan dibuat dari buah-buahan yang layak dikonsumsi serta harus diberi label yang semestinya (Desrosier, 1988). Hal ini dapat terjadi dikarenakan beberapa hal yaitu sebagai berikut :

1. Tahap fermentasi I tidak dilakukan pemisahan alkohol dengan larutan dimana seharusya dilakukan dengan menggunakan destilasi.

2. Tahap fermentasi II tidak dilakukan destilasi untuk membunuh bakteri yang merugikan dan mendapatkan kadar asam asetat yang lebih murni

3. Praktikan tidak melakukan destilasi dikarenakan keterbatasan tempat dan waktu yang tidak memungkinkan untuk dilakukan.

4. Tidak digunakan bakteri spesifik yang mengasilkan asam cuka. 


\section{Kesimpulan}

Berdasar hasil penelitian dapat disimpulkan bahwa buah salak dan pisang kepok besera kulitnya dapat dibuat sebagai bahan pembuatan cuka buah alami dengan kadar 0,042 \%, beraroma kurang sedap, laruta berwarna putih dan $\mathrm{pH}$ 4,5. Kadar tersebut belum memenuhi kadar cuka yang dipasarkan dan dikonsumsi masyarakat yaitu minimal $4 \%$ (4 g asam asetat per $100 \mathrm{ml}$ ).

\section{Daftar Pustaka}

Desrosier, N.W. 1988. Teknologi Pengawetan Pangan. Jakarta. Universitas Indonesia Press. 637

Hasfita, Fkiri, Leni Maulindan dan Ayu Sari Devi. Pemanfaatan Buah Seri Untuk Pembuatan Asam Asetat menggunakan Bakteri Accetobacter xylinum. Jurnal Teknik Kimia Universitas Malikussaleh.

Humairani, Rindhira Z. 2007. Pengaruh Penambahan Ekstrak Antioksidan Kulit Pisang (Musa paradisiaca) pada Minyak Ikan Terhadap Stabilitas Oksidasi Dengan Katalis Panas dan Cahaya. Skripsi. Sekolah Pascasarjana, Institut Pertanian Bogor. Bogor.

Nurismantoro, Rudi dkk. 2014. Pembuatan Aasam Cuka Pisang Kepok dengan Kajian Lama Fermentasi dan Konsentrasi Inkokulum. Jurnal Rekapangan Vol.8 No 2. Surabaya:UPN Vetrean

Rahayu, Fiti Izmi. 2015. Pemanfaatan Salak (Salacca zalacca) sebagai Bahan Alternatif Pembuatan Cuka Buah dengan Penambahan Konsentrasi Acetobacter aceti yang Berbeda. Skripsi. Surakarta :Fakultas Keguruan dan Ilmu Pendidikan Universitas Muhammadiyah Surakarta.

Rahmawati, Rani. 2015. Pemanfaatan Kulit Singkong (Manihot Utilissima) Sebagai Bahan Alternatif Pembuatan Cuka Dengan Penambahan Konsentrasi Acetobacter
Acety yang Berbeda. Skripsi. Surakarta : Program Studi Pendidikan Biologi Fakultas Keguruan Dan Ilmu Pendidikan Universitas Muhammadiyah Surakarta.

Rukmana, R. 1999. Salak Prospek Agribisnis dan Teknik Usaha Tani. Yogyakarta : Kanisus.

Santoso, H.B. 1995. Cuka Pisang. Yogyakarta : Kanisus.

Sutowijoyo,Danang. 2013. Kriteria Kematangan Pasca Panen Pisang Raja Bulu dan Pisang Kepok. Skripsi. Bogor :Departemen Agronomi dan Hortikultura Fakultas Pertanian, Institut Pertanian Bogor.

Zubaidah, Elok. 2010. Kajian Perbedaan Kondisi Fermentasi Alkohol dan Konsentrasi Inokulum pada Pembuatan Cuka Salak (Salacca zalacca). Jurnal Teknologi Pertanian Vol. 11 (2) : $94-100$. 